\title{
Spotlight of Twenty First Century Betacoronaviruses
}

\section{T Pratheep* and G Venkat Kumar}

Department of Biotechnology, PRIST Deemed to University, India

*Corresponding Author: T Pratheep, Department of Biotechnology, PRIST Deemed

to University, India.
Received: October 23, 2020

Published: November 27, 2020

(C) All rights are reserved by $\mathbf{T}$ Pratheep

and G Venkat Kumar.

\begin{abstract}
Coronavirus (CoV) have previously been considered as relatively non-virulent respiratory pathogens to human. Beginning of the $21^{\text {st }}$ century, three CoV's have crossed the species barrier to cause high pathogenic and mortality rates in human populations. However, two epidemic of severe respiratory tract infection caused by severe acute respiratory syndrome coronavirus (SARS-CoV) and Middle East respiratory syndrome coronavirus (MERS-CoV) deadly diseases in human. Another one, named SARS-CoV-2 is ongoing outbreak of atypical pneumonia and pandemic to global population. This brought CoV alert and highlighted the importance of controlling infectious pathogens at worldwide. In this review, we focus on present understanding of the epidemiology, pathology, transmission, prevention, and treatment of SARS-CoV, MERS-CoV and SARS-CoV-2.
\end{abstract}

Keywords: Coronavirus; SARS-CoV; MERS-CoV; SARS-CoV-2; COVID-19

\section{Introduction}

Coronavirus $(\mathrm{CoV})$ is considered of high veterinary impact exclusively, now recognized as zoonotic threats of pandemic potential to world population. CoV is crown like morphology, enveloped and single strand RNA genome virus, are 80 to $160 \mathrm{~nm}$ in size. It can be classified into four genera: alpha, beta, gamma, and delta CoV [1]. Previously identified alpha CoV: hCoV-NL63 and hCoV$229 \mathrm{E}$ and beta $\mathrm{CoV}$ ( $\beta \mathrm{CoV}$ ): HCoV-OC43, HKU1 cause self-limiting common cold-like illnesses [2]. However, other $\beta$ CoV's are Severe Acute Respiratory Syndrome Coronavirus (SARS-CoV), Middle East respiratory syndrome Coronavirus (MERS-CoV) and SARS-CoV-2 infection leads to life threatening disease and have pandemic potential.

SARS-CoV is transmission from bats to human and nosocomial communication between individuals, accompanied by high fatality rates. It's emerged from Guangdong province of southern China in 2002 and spread to 33 countries [3]. Combined global attempt led to fast identification of SARS-CoV and remarkable scientific advancements in epidemic prevention. Remarkably, SARS-CoV epi- demic was ended in 2004 and infections controlled. One decade later in 2012, another zoonosis and virulent pathogenic virus, MERSCoV was identified in Saudi Arabia [4] and spread 27 countries. MERS-CoV infected the humans through direct or indirect contact with infected dromedary camels [5].

Recent emergence of SARS-CoV-2 is significant threat to global public health. SARS-CoV-2 reported a cluster of human population in Wuhan City, China on 2019 [6], and designated as CoV disease 2019 (COVID-19). The SARS-CoV-2 origin is under investigation but associated to a wet animal market [7]. All three $\beta$ CoV's are share common features contribute to nosocomial transmission, viral replication, immunopathology and cause lower respiratory tract infection. Infection is begins with binding of viral particles to host surface cellular receptors called spike (S) glycoprotein [8]. Angiotensin Converting Enzyme 2 (ACE 2) binds with S protein and gets conformational changes for membrane fusion [9]. This review highlights the epidemiology and pathogenesis of $\beta \mathrm{CoV}$, including our current understanding of their biological characteristics, transmission, replication, prevention and treatments. 


\section{Human epidemiology}

The transmission mechanism and epidemiology character of SARS-CoV, MERS-CoV and SARS-CoV-2 are tabulated (Table 1). Transmission from animals to human, direct contact with intermediary host might be one route. In twenty first century, first $\beta \mathrm{CoV}$ causing infectious disease, SARS-CoV originated in Foshan, Guangdong province in China at November 2002, resulted in 813 deaths among more than 8447 patients in 33 countries [3]. SARS-CoV was outbreaks in two times, 1) First outbreak begins in Guangdong province in late 2002. 2) Second outbreak during in late 2003 to early 2004, again reported from Guangdong province, in individuals with animal contacts with different SARS-CoV strains [10].

The second $\beta \mathrm{CoV}$, MERS-CoV emerged in June 2012 in Jeddah, Saudi Arabia when a 60 year-old man presented with severe pneumonia [11]. MERS-CoV spread around 27 countries but around $80 \%$ of cases have occurred in Saudi Arabia. The consumption of camel milk, urine, or uncooked meat may be conducive to transmission. It's rarely transmitted among people and mostly occurs in family members and health care workers. Nosocomial infections were reported, and overseas travel led to the transmission of MERS-CoV to Middle East/North Africa, causing it to become a global pathophoresis [12]. MERS-CoV affects 2519 people and approximately $35 \%$ of patients were died (WHO).

Ongoing outbreak of SARS-CoV-2 is pandemic to world population and biological characters close resemblance to SARS-CoV. SARS-CoV-2 was reported from wet seafood market in Wuhan City, Hubei Province of China in December 2019. The SARS-CoV-2 source of transmission still unknown but linked to a wet animal market [7]. It has a $96 \%$ similarity to a bat $\mathrm{CoV}$ and $70 \%$ genetic similarly with SARS-CoV [13-15].

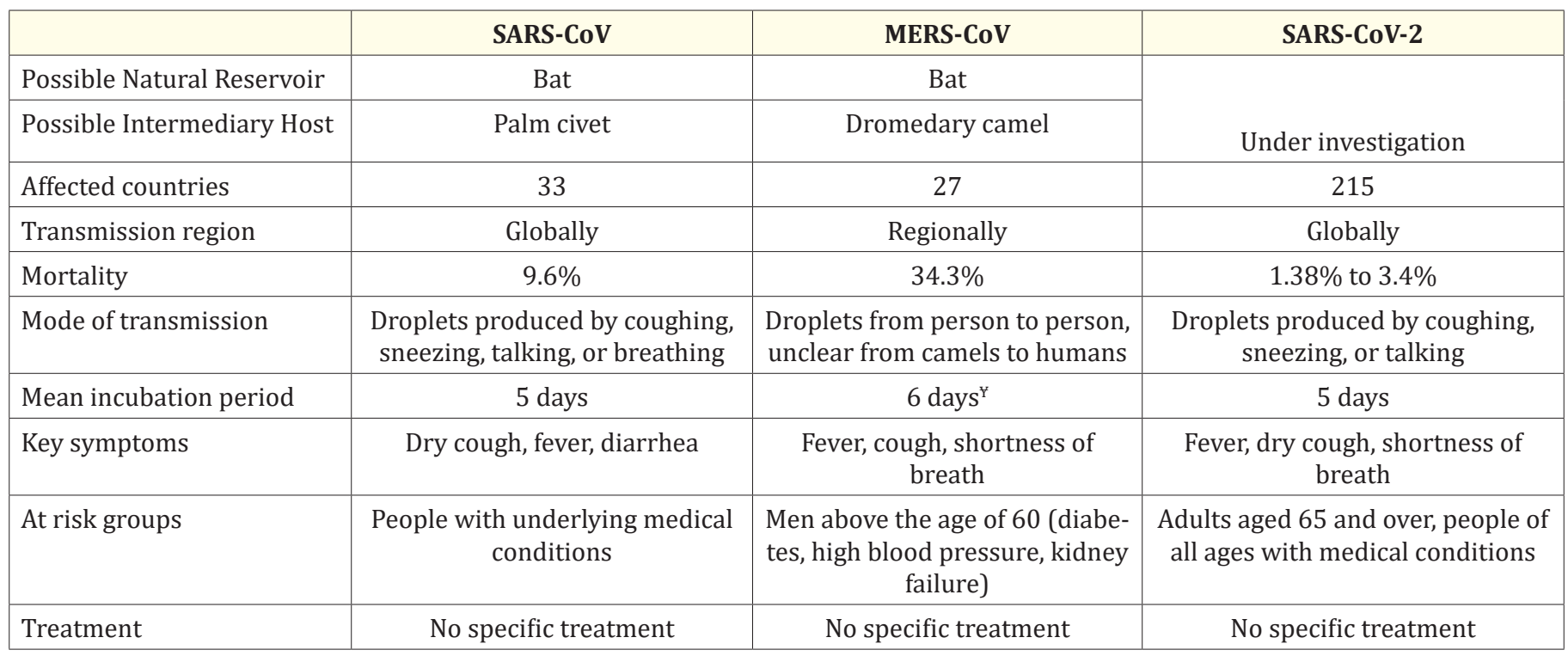

Table 1: Epidemiology characteristics of the $\beta \mathrm{CoV}$ 's.

Reference: Assiri., et al. [12]; Song., et al. [49].

\section{Pathogenesis of $\beta$ CoV's}

Our existing knowledge of the pathogenesis of CoV's infection still unclear, we tabulated what is presently

CoV's are the single strand (positive sense) RNA viruses (26-32 kb) as they are about $125 \mathrm{~nm}$ in diameter. Based on its phylogenetic relationships and genomic structures the three CoV's are belongs to genera Betacoronavirus. $\beta \mathrm{CoV}$ have largest genomes (26.4 - 31.7 $\mathrm{kb}$ ) among all known RNA viruses, with $\mathrm{G}+\mathrm{C}$ contents varying from $32 \%$ to $43 \%$ [16]. Genetically, SARS-CoV-2 is similar to SARS-CoV (about 79\%) and MERS-CoV (about 50\%) (Figure 1). $\beta$ CoV's contain structural protein are S protein, nucleocapsid protein $(\mathrm{N})$, envelope protein (E), and membrane protein (M). The S protein major role is receptor binding and following viral entry into host cells, therefore a major therapeutic target. The $\mathrm{N}$ protein is necessary for 
RNA synthesis, $\mathrm{M}$ and $\mathrm{E}$ proteins play vital roles in viral assembly [14]. Accessory proteins are help the virus escape the immune system by being harmful to the innate immune response [17]. Hemagglutinin esterase contributes to virion adhesion, and same time enhances sialate o-acetylesterase activity towards clustered sialoglycotopes [18].

\section{Life cycles of $\beta$ CoV's}

$\beta C o V$ 's are emerging communicable viral disease characterized by severe clinical demonstration of the lower respiratory tract, resulting in diffuse alveolar damage. $\beta$ CoV's enter target cells through an endosomal pathway. Viruses are binds to human cell by receptor protein and allow virus to enter and infect the cells.
SARS-CoV and MERS-CoV source of transmission are tabulated (Table 1), SARS-CoV-2 source is still unknown. Three $\beta \mathrm{CoV}$ 's are spreads through respiratory secretions, such as droplets, via human to human contact. S proteins of SARS-CoV and SARS-CoV-2 are binding to ACE2 of human cells followed by membrane fusion [19] (Figure 1). The SARS-CoV-2 S protein has a higher affinity for ACE2, while lower affinity for SARS-CoV [20]. In respiratory tract, ACE2 is widely expressed on the epithelial cells of alveoli, trachea, bronchi, bronchial serous glands, and alveolar monocytes and macrophage [21]. After virus enters the human cell and uncoats, genome replication and transcription takes place at cytoplasmic membranes. The mature virions are forms by budding then released from primary cells and infect new target cells [22].

\begin{tabular}{|c|c|c|c|c|}
\hline & & SARS-CoV & MERS-CoV & SARS-CoV-2 \\
\hline \multicolumn{2}{|c|}{ Virus particle size (in nm) } & $80-90$ & $118-136 \mathrm{~nm}$ & 60 to $140 \mathrm{~nm}$ \\
\hline \multicolumn{2}{|c|}{ Length of nucleotides } & 29,727 & 30,119 & 29,844 \\
\hline \multicolumn{2}{|c|}{ Open reading frames } & 11 & 11 & 11 \\
\hline \multicolumn{2}{|c|}{ Structural protein } & 4 & 4 & 4 \\
\hline \multicolumn{2}{|c|}{ Spike protein (length of amino acids) } & 1255 & 1353 & 1273 \\
\hline \multirow[t]{2}{*}{ S1 subunit } & Receptor-binding domain & $318-510$ & $367-588$ & $331-524$ \\
\hline & Receptor-binding motif & $424-494$ & $484-567$ & 437-509 \\
\hline \multirow[t]{2}{*}{ S2 subunit } & Heptad repeat 1 domains & 892-1013 & 984-1104 & $894-966$ \\
\hline & Heptad repeat 2 domains & $1145-1195$ & $1246-1295$ & $1145-1195$ \\
\hline \multicolumn{2}{|c|}{ Non-structural proteins (NSPs) } & 5 & 16 & 14 \\
\hline \multicolumn{2}{|c|}{ Accessory proteins } & 8 & 5 & 6 \\
\hline \multicolumn{2}{|c|}{ A characteristic gene order } & \multicolumn{3}{|c|}{$\begin{array}{l}\text { 50-replicase ORF1ab, spike (S), envelope (E), membrane (M), and } \\
\text { nucleocapsid (N)-30 }\end{array}$} \\
\hline
\end{tabular}

Table 2: Genomic characteristics of $\beta \mathrm{CoV}^{\prime}$ 's.

Reference: Mousavizadeh and Ghasemi, [14]; Neuman., et al. [51].

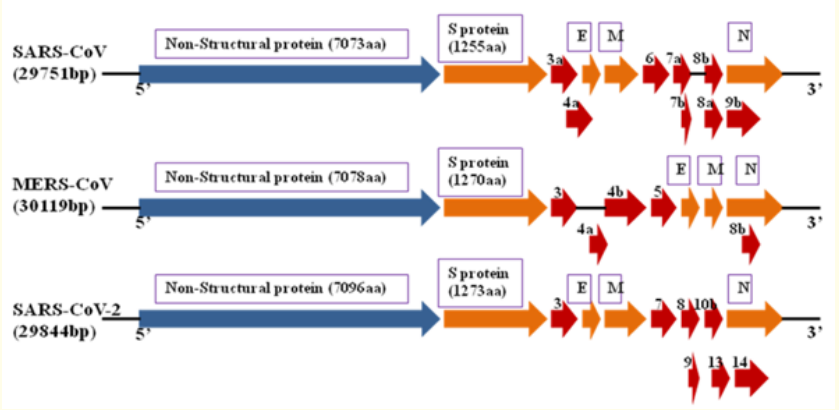

Figure 1: The coding and non-coding region of SARS-CoV, MERS$\mathrm{CoV}$ and SARS-CoV-2. The numbers of base pairs among coronaviruses are shown. The differences in the arrangement of structural protein: envelope $(\mathrm{E})$, membrane $(\mathrm{M})$, and nucleoprotein $(\mathrm{N})$ among $\beta \mathrm{CoV}$.

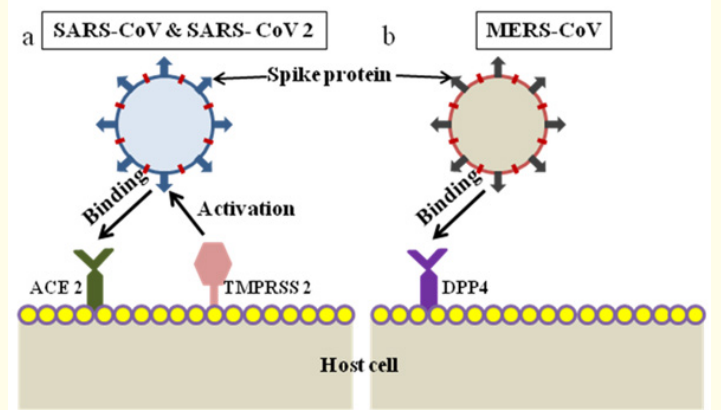

Figure 2: a) SARS-CoV and SARS-CoV-2 S protein are binding with ACE2 and cellular protease TMPRSS2 for their activation. b) MERS-CoV S protein is binding with DPP4. ACE2: Angeiotensin converting enzyme 2; TMPRSS2: Transmembrane protease, serine 2; DPP4: Dipeptidyl peptidase 4. 
MERS-CoV infect to human cell by multifunctional cell surface receptor protein, dipeptidyl peptidase 4 (DPP4), which is expressed on epithelial cells in the kidney, alveoli, small intestine, liver, and prostate, and on activated leukocytes [23]. MERS-CoV S protein bind to DPP4 of epithelial cells, forming the double membrane vesicle in host cell, and releasing the RNA enclosed in nucleocapsid. The viral RNA replicate, transcript followed by translation; endoplasmic reticulum support the assembly of virus particle and MERS-CoV is released out of the host cell by exocytosis [24].

\section{$\beta$ CoV's spike protein}

$\beta C o V$ 's transmembrane $S$ glycoprotein is forms homotrimers protruding from the viral surface. $\mathrm{S}$ protein comprises two functional subunits responsible for binding to host cell receptor (S1 subunit) and fusion of the viral and cellular membranes (S2 subunit). In many $\beta \mathrm{CoV}$ 's $\mathrm{S}$ protein is cleaved at the boundary between the S1 and S2 subunits, which remain non-covalently bound in prefusion conformation [25]. All $\beta \mathrm{CoV}$ 's $\mathrm{S}$ is cleaved by host proteases at $\mathrm{S} 2$ ' site located next to upstream of the fusion peptide. This cleavage is activating the protein for membrane fusion through extensive irreversible conformational changes [26].

SARS-CoV, MERS-CoV and SARS-CoV-2 S proteins emphasize the close relationship in structural similarity and sequence conservation. S protein is approximately $180 \mathrm{kDa}$ glycoprotein and it is composed of two domains, S1 and S2 [27]. S1 contain the receptor binding domain, which binds to peptidase domain of ACE 2 , and S2 is responsible for membrane fusion [28]. S1 subunit is recognizing a variety of binding and entry receptors, depending on the viral species. When S1 binds to ACE2 receptor, S2 is cleaved by host proteases, process that is critical for viral infection. $S 2$ subunit contains two regions with 4,3 heptad repeat (HR), designated as HR1 and HR2. Both are conserved in position and sequence among the members of three $\beta \mathrm{CoV}$ antigenic clusters. A number of studies have shown that HR1 and HR2 regions are involved in viral fusion [29].

\section{Antiviral drugs}

During the SARS-CoV-2 epidemic, clinical studies show that the lopinavir-ritonavir combination therapy with ribavirin in SARS patients decreased the virus load and clinical symptoms when compared with standard treatment cases [30,31]. Lopinavir-ritonavir was an HIV-1 protease inhibitor but it was reported to target SARS-CoV-2 nonstructural protein 3CLpro [31]. Similarly during the MERS-CoV outbreak, MERS patient treated with lopinavirritonavir showed virus replication decreased, viral clearance from sputum and serum, and increased immune response [31]. Other clinical study from Korea also reported that the lopinavir-ritonavir combination therapy is showing antiviral activity [32]. Later, a combination treatment of Interferon/ribavirin/ lopinavir-ritonavir was recommended officially for MERS therapy in South Korea during the 2015 disease spread [33]. Ribavirin is a guanosine analog, which inhibits RNA synthesis by viral RdRp as well as inhibits mRNA capping. Ribavirin was primarily used as a treatment option in Saudi Arabia and UAE [34,35]. Interferon (IFN) is a group of lowmolecular glycoproteins mainly shows antiviral acidity by inducing antiviral production effector proteins, inhibits viral replication and activates cellular. The same was further recommended in the Saudi Arabia for MERS treatment [36]. In the case of COVID-19, Clinical trial study from China shows that no improvement was observed with lopinavir-ritonavir treatment compared to the standard care [37]. Hydroxychloroquine a well-known anti-malarial drugs was reported to show antiviral activity in small non-randomized French population study [38]. However, other study from the French population showed no improvement after hydroxychloroquine treatment compared to standard care [39]. Remdesivir is a nucleotide analogue prodrug that inhibits viral RNA polymerases. Non-randomized clinical study including COVID 19 patients form US, UK and Japan shows a $68 \%$ of clinical improvement compared to the standard care, the study funded by Gilead Sciences [40]. Gilead Sciences stated that they are conduction large scale study in 180 trail sites with 5,600 patient enrollments from various part of the world.

\section{Vaccine development}

To date, there is no specific treatment proven effective against this SARS-CoV and MERS-CoV disease. In addition, no vaccine has been licensed to prevent this viral infection so far. In 2002 2003, during the SARS-CoV outbreak, in four months the genome sequence of the coronavirus was sequenced to develop antigens. Many pharma companies and laboratories started to develop vaccine against the SARS-COV. Various vaccines based on inactivated virus, recombinant viral vectors, DNA, virus-like particles, soluble proteins and DNA vaccines were studied. But, vaccines based on an inactivated SARS virus, DNA vaccine and soluble proteins were entered the phase I clinical stages [41-43]. The first human trial of an inactivated SARS vaccine was conducted in Beijing (December, 2004), but by that time the epidemic had ended and research into other diseases had been prioritized so that it had been dropped 
[44]. Similarly, for MERS outbreak in Saudi Arabia (2012), similar vaccine strategies were considered for vaccination, including an inactivated virus vaccine, a live-attenuated vaccine, a viral vector such as adenovirus, bacterial vectors, recombinant MERS-CoV proteins, MERS-CoV DNA vaccines [45]. Among that, adenovirus vaccine (ChAdOx1 MERS, which uses a replication-deficient chimpanzee adenovirus) was in Phase 1 human clinical trials in the United Kingdom and Saudi Arabia. However, the other vaccines are in development and clinical trial phases, so far, no vaccine was licensed for MERS therapeutics yet. As compared to SARS-CoV and MERS-CoV, SARS-CoV-2 is a pandemic disease, infected more than 3.4 million people worldwide. Hence, finding a safe and effective vaccine to prevent SARS-CoV-2 infection is a crucial public health importance. China successfully sequenced SARS-CoV-2 genome and submitted to GenBank on 5 January 2020 [46]. As, SARS-CoV-2 ' $\mathrm{S}$ ' glycoproteins is responsible for virus binding and host cell entry [47]. The glycoprotein is cleaved into 'S1' and 'S2' subunit, 'S1' and 'S2' subunit shares $70 \%$ and $99 \%$ similarity with SARS-CoV, respectively [48]. Hence, developing a new vaccine targeting the ' $S$ ' glycoprotein may enhance the antiviral effect against SARS-CoV-2.

\section{Conclusion}

COVID-19 has attained the status of a global pandemic over a short period. A proper understanding of the pathogenesis of CoV's are indicated in this study and related molecular mechanisms will definitely help in the development of therapeutics against the novel CoV's.

\section{Acknowledgments}

The authors acknowledge the PRIST Deemed to University Management.

\section{Conflict of Interest}

The authors declare that there is no conflict of interest.

\section{Bibliography}

1. Woo PC., et al. "Comparative analysis of complete genome sequences of three avian coronaviruses reveals a novel group 3c coronavirus". Journal of virology 83.2 (2009): 908-917.

2. Gorse GJ., et al. "Human coronavirus and acute respiratory illness in older adults with chronic obstructive pulmonary disease". Journal of Infectious Disease 199.6 (2009): 847-857.

3. Chen YC., et al. "Certainties and uncertainties facing emerging respiratory infectious diseases: lessons from SARS". Journal of Formos Medical Association 107.6 (2008): 432-442.
4. Zaki AM., et al. "Isolation of a novel coronavirus from a man with pneumonia in Saudi Arabia". New England Journal of Medicine 367.19 (2012): 1814-1820.

5. Haagmans BL., et al. "Middle East respiratory syndrome coronavirus in dromedary camels: an outbreak investigation". The Lancet Infectious Diseases 14.2 (2014): 140-145.

6. Wang C., et al. "A novel coronavirus outbreak of global health concern". Lancet 395.10223 (2020): 470-473.

7. Zhu N., et al. "A novel coronavirus from patients with pneumonia in China, 2019". New England Journal of Medicine 382.8 (2020): 727-733.

8. Lu G., et al. "Bat-to-human: spike features determining 'host jump' of coronaviruses SARS-CoV, MERS-CoV, and beyond". Trends in Microbiology 23.8 (2015): 468-478.

9. Dimiter S D. "The Secret Life of ACE2 as a Receptor for the SARS Virus”. Cell 115.6 (2003): 652-653.

10. Jiang S., et al. "SARS vaccine development". Emerging Infection Disease Journal 11.7 ( 2005): 1016-1020.

11. Mackay I M and Arden K E. "MERS coronavirus: diagnostics, epidemiology and transmission”. Virology Journal 12 (2015): 222.

12. Assiri A., et al. "Hospital outbreak of Middle East respiratory syndrome Coronavirus". New England Journal of Medicine 369.5 (2013): 407-416.

13. MERS situation update (2019).

14. Mousavizadeh L and Ghasemi S. "Genotype and phenotype of COVID-19: Their roles in pathogenesis". Journal of Microbiology, Immunology Infection S1684-1182.20 (2020): 3008230087.

15. SARS-CoV-2 situation update (2020).

16. Woo PCY., et al. "Coronavirus genomics and bioinformatics analysis”. Viruses 2.8 (2010): 1804-1820.

17. Liu DX., et al. "Accessory proteins of SARS-CoV and other coronaviruses". Antiviral Research 109 (2014): 97-109.

18. Bakkers MJG., et al. "Betacoronavirus Adaptation to Humans Involved Progressive Loss of 692 Hemagglutinin-Esterase Lectin Activity". Cell Host Microbe 21.3 (2017), 356-366.

19. Hoffmann M., et al. "SARS-CoV-2 cell entry depends on ACE2 and TMPRSS 2 and is blocked by a clinically proven protease inhibitor". Cell 181.2 (2020): 271-280. 
20. Chen Y., et al. "Emerging coronaviruses: genome structure, replication, and pathogenesis". Journal of Medical Virology 92.4 (2020): 418-423.

21. Liu L., et al. "Epithelial Cells Lining Salivary Gland Ducts Are Early Target Cells of Severe Acute Respiratory Syndrome Coronavirus Infection in the Upper Respiratory Tracts of Rhesus Macaques". Journal of Virology 85.8 (2011): 4025-4030.

22. McIntosh K and Peiris JSM. “Coronaviruses". In. Douglas D. Richman, Richard J. Whitley, Frederick G. Hayden (eds.). Clinical Virology. 3rd Ed, American Society of Microbiology (2009): 1155-1171.

23. Meyerholz DK., et al. "Dipeptidyl Peptidase 4 Distribution in the Human Respiratory Tract: Implications for the Middle East Respiratory Syndrome". American Journal of Pathology 186.1 (2016): 78-86.

24. Durai P., et al. "Middle East respiratory syndrome corona virus: transmission, virology and therapeutic targeting to aid in outbreak control". Experimental and Molecular Medicine 47 (2015): 181.

25. Bosch BJ., et al. "The coronavirus spike protein is a class I virus fusion protein: structural and functional characterization of the fusion core complex". Journal of Virology 77.16 (2003): 8801-8811.

26. Kirchdoerfer RN., et al. "Pre-fusion structure of a human coronavirus spike protein”. Nature 531.7592 (2016): 118-121.

27. Belouzard S., et al. "Activation of the SARS coronavirus spike protein via sequential proteolytic cleavage at two distinct sites". Proceedings of the National Academy of Sciences of the United States of America 106.14 (2009): 5871-5876.

28. Fang Li. "Receptor Recognition Mechanisms of Coronaviruses: a Decade of Structural Studies". Journal of Virology 89.4 (2015): 1954-1964.

29. Zheng B J., et al. "Synthetic peptides outside the spike protein heptad repeat regions as potent inhibitors of SARS-associated coronavirus". Antiviral Therapy 10.3 (2005): 393-403.

30. Chan KS., et al. "Treatment of severe acute respiratory syndrome with lopinavir/ritonavir: a multicentre retrospective matched cohort study". Hong Kong Medical Journal 9.6 (2003): 399-406.

31. Chu CM., et al. "Role of lopinavir/ritonavir in the treatment of SARS: initial virological and clinical findings". Thorax 59.3 (2004): 252-256.
32. Kim UJ., et al. "Combination therapy with 1lopinavir/ritonavir, ribavirin and interferon-alpha for Middle East respiratory syndrome". Antiviral Therapy 21.5 (2016): 455-459.

33. Chong YP., et al. "Antiviral treatment guidelines for Middle East respiratory syndrome". Infection Chemotherapy 47.3 (2015): 212-222.

34. Totura AL and Bavari S. "Broad-spectrum coronavirus antiviral drug discovery". Expert Opinion on Drug Discovery 14.4 (2019): 397-412.

35. Arabi YM., et al. "Treatment of Middle East respiratory syndrome with a combination of lopinavir/ritonavir and interferon-beta1b (MIRACLE trial): statistical analysis plan for a recursive two-stage group sequential randomized controlled trial". Trials 21.1 (2020): 8.

36. Dyall J., et al. "Middle East Respiratory Syndrome and Severe Acute Respiratory Syndrome: Current Therapeutic Options and Potential Targets for Novel Therapies". Drugs 77.18 (2017): 1935-1966.

37. Cao B., et al. "A trial of lopinavir-ritonavir in adults hospitalized with severe Covid-19". New England Journal of Medicine 382.19 (2020): 1787-1799.

38. Gautret P., et al. "Hydroxychloroquine and azithromycin as a treatment of COVID-19: results of an open label non-randomized clinical trial". International Journal of Antimicrobial Agent 20 (2020): 105949.

39. Molina J., et al. "No evidence of rapid antiviral clearance or clinical benefit with the combination of hydroxychloroquine and azithromycin in patients with severe COVID-19 infection". Médecine et Maladies S0399-077X.20 (2020): 30085-30088.

40. Grein J., et al. "Compassionate use of Remdesivir for patients with severe Covid-19". New England Journal of Medicine 382 (2020): 2327-2336.

41. Lin JT., et al. "Safety and immunogenicity from a phase I trial of inactivated severe acute respiratory syndrome coronavirus vaccine". Antiviral Therapy 12.7 (2007): 1107-1113.

42. Martin JE., et al. "A SARS DNA vaccine induces neutralizing antibody and cellular immune responses in healthy adults in a Phase I clinical trial". Vaccine 26.50 (2008): 6338-433.

43. NIH-ClinicalTrials.gov, Phase I Dose Escalation SARS-CoV Recombinant S Protein, With and Without Adjuvant, Vaccine Study (2013). 
44. Orellana C. "Phase I SARS vaccine trial in China". Lancet Infectious Disease 4.7 (2004): 388.

45. Padron-Regalado E. "Vaccines for SARS-CoV-2: Lessons from Other Coronavirus Strains". Infection Disease Therapy (2020): $1-20$.

46. Wu F., et al. "A new coronavirus associated with human respiratory disease in China". Nature 579 (2020): 265-269.

47. Gralinski LE and Menachery VD. "Return of the coronavirus: 2019-nCoV”. Viruses 12 (2020): 135.

48. Shang W., et al. "The outbreak of SARS-CoV-2 pneumonia calls for viral vaccines". NPJ Vaccines 5 (2020): 18.

49. Song Z., et al. "From SARS to MERS, Thrusting Coronaviruses into the Spotlight”. Viruses 11.1 (2019): E59

50. How do SARS and MERS compare with COVID-19? (2020).

51. Neuman BW., et al. "Supramolecular architecture of severe acute respiratory syndrome coronavirus revealed by electron cryomicroscopy". Journal of Virology 80.16 (2006): 79187928.

\section{Assets from publication with us}

- Prompt Acknowledgement after receiving the article

- Thorough Double blinded peer review

- Rapid Publication

- Issue of Publication Certificate

- High visibility of your Published work

Website: https://www.actascientific.com/

Submit Article: https://www.actascientific.com/submission.php

Email us: editor@actascientific.com

Contact us: +919182824667 